\title{
LA CORRUPCIÓN Y EL CONTROL JUDICIAL EN ARGENTINA. SU ESTUDIO A PARTIR DE LOS FALLOS DE EMIR FUAD YOMA, MARÍA JULIA ALSOGARAY Y CRISTOBAL LOPEZ ${ }^{74}$
}

\author{
Ricardo Sebastián Piana ${ }^{75}$ \\ Martín Arévalo ${ }^{76}$
}

Recebido em: 16/11/2018

Aprovado em: 17/12/2018

\section{RESUMEN}

En el presente artículo estudiamos el fenómeno de la corrupción en Argentina a partir del análisis de tres fallos del Poder Judicial relevantes tanto por repercusión mediática como por su doctrina, análisis que nos permitirá inferir algunas pautas sobre el funcionamiento del Poder Judicial. Se utilizará como metodología la hermenéutica para el estudio de los fallos desde una perspectiva teórica que integra el estudio del derecho dentro de las ciencias sociales, encuadrando el control judicial como un fenómeno político. El artículo se estructura en 3 secciones. La primera, presenta el problema de la corrupción desde una perspectiva teórica y normativa destacando su vinculación con el sistema político; la segunda, desde el control y el Poder Judicial y la necesidad de identificar el control como un control no político aún cuando sea necesario estudiar el fenómeno desde los aspectos políticos involucrados; en la tercena nos abocamos al estudio de los fallos. Concluimos que las doctrinas de fallos que reseñamos permitirían crear una red sólida para el controlar judicial de la corrupción, aunque identificamos un patrón temporal que afecta la eficacia del control.

Palabras clave: Poder Judicial. Corrupción. Control. Argentina.

\footnotetext{
${ }^{74}$ Artículo de investigación. Resultados parciales del proyecto de investigación "GLOCAL. La influencia de las políticas y buenas prácticas globales sobre las políticas públicas en la Provincia de Buenos Aires" en el marco del Programa de incentivos al docente-investigador del Ministerio de Educación, Ciencia y Tecnología de la Nación, dirigido por Ricardo Sebastián Piana y financiado por la Universidad Nacional de La Plata. Fecha de terminación de la investigación: 31/12/2017.

${ }^{75}$ Abogado y Doctor en Ciencia Jurídica de la Universidad Nacional de La Plata y Doctor en Ciencia Política de la Universidad del Salvador - Argentina. Actual director de la investigación "Instituciones, Legislación y Políticas Públicas en la Provincia de Buenos Aires: Un estudio en el micro y macro nivel.”. Instituto de Integración Latinoamericana, Facultad de Ciencias Jurídicas y Sociales, Universidad Nacional de La Plata.

${ }^{76}$ Licenciado en Ciencia Política, Universidad del Salvador - Argentina. Miembro del proyecto "Instituciones, legislación y políticas públicas en la Provincia de Buenos Aires: Un estudio a partir de los cambios políticos institucionales 2015-2019" de la Universidad del Salvador, dirigido por Ricardo Sebastián Piana. Facultad de Ciencias Jurídicas, Universidad del Salvador.
} 


\section{INTRODUCCIÓN}

Según una auditoría del Consejo de la Magistratura de la Nación Argentina, solo el 2\% de los acusados de corrupción en Argentina son condenados. Este resultado, objetivamente bajo, podría ser resultado de un uso político de las acusaciones de corrupción para "manchar" a políticos en el cargo por parte de una oposición inescrupulosa. Este porcentaje adquiere un carácter más preocupante cuando el mismo estudio revela que sólo el $32 \%$ sobre el total de los juicios terminaron con funcionarios sentenciados culpables. Ello supone que parte del Poder Judicial (jueces federales y fiscales) investigaron, creyeron verosímil imputar, procesar e incluso elevar a juicio oral y público un juicio que involucra un hecho de corrupción. Estamos todavía con el margen de la presunción de inocencia y el derecho del juzgado a ser declarado inocente. Pero el resultado de la auditoría es verdaderamente alarmante si uno de cada tres funcionarios fueron absueltos por la prescripción de los expedientes ${ }^{77}$. Este último dato es un claro caso de no hacer por parte del Poder Judicial, sea ese funcionario realmente culpable o realmente inocente: el derecho a la verdad material se pierde tanto para la sociedad como para el imputado.

Otro dato preocupante y vinculado con los resultados anteriores: según el Informe 2017 de la ONG Latinobarómetro, en Argentina la confianza en el Poder Judicial sólo llega al $25 \%$, en igual porcentaje que el promedio regional, por debajo en la confianza en el Congreso (26\%), en el Gobierno (32\%), en la policía (38\%) o las fuerzas armadas (50\%) y sólo por arriba en la confianza que los argentinos tienen en los partidos políticos (18\%) (Conf. Latinobarómetro, 2017).

Estos datos nos dan cuenta de la importancia de estudiar la vinculación entre corrupción y Poder Judicial, especialmente cuando las democracias de esta Región están enfrentando los desafíos del último cuarto de siglo y comienzos del presente: globalización, tecnologías, amenaza de guerra nuclear, la ideología del «fin de las ideologías», megaciudades, terrorismo, choque cultural, calentamiento global, nuevos nacionalismos y matanzas étnicas, migraciones, desigual distribución de la riqueza. Todos estos temas han modificado el contexto de la democracia, pero tal vez el problema central provenga del propio hard core ideológico del modelo democrático republicano: cuando falla el principio del control público, es difícil mantener el postulado de que se gobierna para el bien de todos.

\footnotetext{
${ }^{77}$ Conf. Diario La Nación e Infobae, 2018. El estudio abarca los en los últimos 20 años, entre 1996 y 2016, y respecto de los juzgados federales de Comodoro Py, ubicados en la Ciudad Autónoma de Buenos Aires, donde residen las autoridades nacionales.
} 
Existe una urgencia por traducir y adaptar tanto la teoría como la práctica de la democracia liberal clásica a las nuevas realidades económicas, sociales y técnicas y para ello, el Poder Judicial tiene un rol central en nuestro sistema político.

El objetivo de este paper es analizar las decisiones de los fallos Emir Fuad Yoma, María Julia Alsogaray y Cristóbal López. Estos fallos, como veremos, son relevantes por ser algunos de los pocos casos desde el retorno de la democracia en Argentina, en 1983 a la fecha, que han tenido una fuerte repercusión mediática y cuya doctrina permite inferir algunas pautas sobre el funcionamiento del Poder Judicial.

Entendemos que a partir de los fallos que estudiamos en éste artículo el Poder Judicial ha marcado una guía y un esquema de poder justamente para controlar la corrupción, en aquellos casos donde no solamente son relevantes para los medios masivos de comunicación, sino aquellos de gravedad institucional que generan un sistema de corrupción establecido en el Estado.

Se utilizará como metodología la hermenéutica para el estudio de los fallos de las causas desde una perspectiva teórica que integra el estudio del derecho dentro de las ciencias sociales. En efecto, recordando las palabras del Dr. Petracchi, ex juez de la Corte Suprema de Justicia de la Nación, los jueces son políticos, lo sepan o no (Abramovich, 1992) y de allí que encuadremos el control judicial como un fenómeno político. El abordaje es exploratorio ya que existen pocos estudios que aborden en Argentina la temática desde esta perspectiva.

El artículo se estructura en 3 secciones. La primera, presenta el problema de la corrupción desde una perspectiva teórica y normativa destacando su vinculación con el sistema político; la segunda, desde el control y el Poder Judicial y la necesidad de identificar el control como un control no político aún cuando sea necesario estudiar el fenómeno desde los aspectos políticos involucrados; en la tercena nos abocamos al estudio de los fallos. Concluimos que las doctrinas de fallos que reseñamos permitirían crear una red sólida para el controlar judicial aunque identificando un patrón temporal que afecta la eficacia del control.

\section{LA CORRUPCIÓN: UN ACERCAMIENTO CONCEPTUAL Y NORMATIVO}

Como ha señalado Posada Carbó (1994), la corrupción no es un fenómeno novedoso ya que su presencia es tan antigua como la prostitución pero hoy el término ha adquirido un sentido más técnico: entendida tradicionalmente como forma de incumplir subrepticiamente 
las reglas establecidas ha pasado a señalar la apropiación indebida de los recursos del Estado por el mal manejo de los funcionarios públicos ${ }^{78}$.

Identificado como un problema propio de los "políticos",79, es recientemente cuando se la comienza a identificar como un problema social y cultural y no ya como un fenómeno individual de desvío moral de una clase, la de los políticos.

La corrupción puede existir en cualquier régimen político, pero afecta más fuertemente al régimen democrático. En efecto, en un sistema donde el bienestar de toda la población es el criterio de legitimación del poder, donde los funcionarios actúan autorizados por medio del voto y las decisiones se toman e imputan a los representados, la corrupción no sólo es una falta ética sino una afrenta a las bases del sistema político.

Según el BID, la corrupción

repercute negativamente sobre todos los intereses nacionales y en algunas instancias, desde el punto de vista del desarrollo económico, esa repercusión asume dimensiones trágicas. Una nación no puede concebir y mantener programas eficaces que inciden en los ámbitos de transporte, educación, agricultura, salud, energía y otras áreas de interés público si los fondos que destina para tales fines se malversan para beneficio personal de contratistas y funcionarios de gobierno (BID, 2008:3).

Además, en términos económicos, se ha señalado que la corrupción aumenta los costos de transacción y la incertidumbre en una economía; lleva a resultados económicos poco eficaces; expulsa a las empresas del sector formal, menoscaba la capacidad del Estado para obtener ingresos y produce un aumento incesante de los impuestos, que paga un número cada vez menor de contribuyentes (conf. Gray y Kaufmann, 1998).

Omar Orsi y Nicolas García (2011) afirman que la calidad de la democracia se encuentra en el grado de respeto de los derechos humanos y en los espacios de participación. Resulta ya conocida la ecuación de Robert Klitgaard (1992): corrupción es igual a monopolio más discrecionalidad menos transparencia. En efecto, la opacidad del sistema político es la contracara de la corrupción, pues permite y facilita las desviaciones pero especialmente, la falta de control. Se ha señalado que

el principio de razonabilidad del Estado se traduce en el derecho ciudadano a la no arbitrariedad del poder, visto el acceso a la información pública no ya como expresión garantística del principio de transparencia de la gestión, sino como derecho ciudadano colectivo, puede ser estudiado como derecho ciudadano a la ética en la gestión pública o derecho a la "no corrupción" (Piana y Amosa, 2018:248).

\footnotetext{
${ }^{78}$ Y agrega: así como es de antigua, la corrupción es también un fenómeno universal (Posada Carbó, 1994:16).

${ }^{79}$ Por ejemplo, Tusell (2009:78) "Si bien se mira, en el origen de cualquier tipo de fenómeno de corrupción está, como factor primordial, ese aislamiento de la política cotidiana de la vida normal de los ciudadanos. Así han llegado a atribuir al mundo de la política unas reglas morales distintas de las aplicables al resto de los mortales".
} 
La corrupción afecta todas las estructuras y corrompe el tejido social cuando se encuentra institucionalizado. Ha sido señalado que

\begin{abstract}
El sistema de corrupción institucionalizado desarrolla estructuras y procesos que le son propios y con el tiempo se consolidan como modalidades corrientes que le permiten de manera continua la obtención de beneficios particulares a expensas de un bien público, institucional, organizacional o grupal. Se desarrolla como un sistema organizativo virtual, secreto y paralelo que se asienta sobre un conjunto de organizaciones ya existentes, de las cuales se nutre para lograr desenvolverse. Supone la trama de una trama de actores y organizaciones que operan en distintos niveles y funciones, estableciendo entre sí procesos transaccionales. (Todarello, 2008:109) $)^{80}$.
\end{abstract}

Uno de los documentos internacionales más relevantes en la materia para nuestra Región, la Convención Interamericana contra la Corrupción (1996), de la cual Argentina es parte $^{81}$, señala que los problemas y las amenazas que plantea la corrupción no es solo a la estabilidad de un país, sino a la seguridad de sus instituciones, los valores de la ética y la justicia, comprometiendo a un desarrollo sostenible y el imperio de la ley.

En el campo de las acciones, la Convención sugiere algunas medidas preventivas, entre las que destacamos, las destinadas a crear, mantener y fortalecer sistemas para proteger a los funcionarios públicos y ciudadanos particulares que denuncien de buena fe actos de corrupción, incluyendo la protección de su identidad y los principios fundamentales de su ordenamiento jurídico interno (III.8) y órganos de control superior, con el fin de desarrollar mecanismos modernos para prevenir, detectar, sancionar y erradicar las prácticas corruptas (III.9). Añade en su artículo V que cada Estado Parte adoptará "las medidas que sean necesarias para ejercer su jurisdicción respecto de los delitos que haya tipificado de conformidad con esta Convención cuando el delito se cometa en su territorio".

La Convención se declara aplicable a los actos de corrupción siguientes:

a. El requerimiento o la aceptación, directa o indirectamente, por un funcionario público o una persona que ejerza funciones públicas, de cualquier objeto de valor pecuniario u otros beneficios como dádivas, favores, promesas o ventajas para sí mismo o para otra persona o entidad a cambio de la realización u omisión de cualquier acto en el ejercicio de sus funciones públicas;

b. El ofrecimiento o el otorgamiento, directa o indirectamente, a un funcionario público o a una persona que ejerza funciones públicas, de cualquier objeto de valor pecuniario u otros beneficios como dádivas, favores, promesas o ventajas para ese funcionario público o para otra persona o entidad a cambio de la realización $u$ omisión de cualquier acto en el ejercicio de sus funciones públicas;

\footnotetext{
${ }^{80} \mathrm{Y}$ añade Todarello (2008) "Cuando nos referimos al estado de corrupción, se intenta caracterizar una situación en la cual los actos de corrupción se erigen y se despliegan de manera habitual, produciendo un escenario donde la corrupción se convierte en sistema, dando lugar a lo que también se denomina sistema institucionalizado de corrupción" (Todarello, 2008:107).

${ }^{81}$ Esta Convención fue aprobada por Ley $\mathrm{N}^{\circ} 24.759$.
} 
c. La realización por parte de un funcionario público o una persona que ejerza funciones públicas de cualquier acto u omisión en el ejercicio de sus funciones, con el fin de obtener ilícitamente beneficios para sí mismo o para un tercero;

d. El aprovechamiento doloso u ocultación de bienes provenientes de cualesquiera de los actos a los que se refiere el presente artículo; y

e. La participación como autor, coautor, instigador, cómplice, encubridor o en cualquier otra forma en la comisión, tentativa de comisión, asociación o confabulación para la comisión de cualquiera de los actos a los que se refiere el presente artículo.

La Convención de Naciones Unidas contra la Corrupción $(2003)^{82}$, también señala que la corrupción plantea amenazas para la estabilidad y seguridad de las sociedades al socavar las instituciones y los valores de la democracia, la ética y la justicia y al comprometer el desarrollo sostenible y el imperio de la ley. En cuanto al necesario contralor, establece que cada Estado Parte, de conformidad con los principios fundamentales de su ordenamiento jurídico, garantizará la existencia de un órgano u órganos encargados de prevenir la corrupción, otorgándoles la independencia necesaria, de conformidad con los principios fundamentales de su ordenamiento jurídico, para que puedan desempeñar sus funciones de manera eficaz y sin ninguna influencia indebida; y añade "Deben proporcionárseles los recursos materiales y el personal especializado que sean necesarios, así como la capacitación que dicho personal pueda requerir para el desempeño de sus funciones" (art. 6.2).

La Resolución $\mathrm{N}^{\circ} 1 / 18$ de la Comisión Interamericana de Derecho Humanos (CIDH) define la corrupción como un complejo fenómeno que afecta a los derechos humanos en su integralidad, así como el derecho al desarrollo; debilita la gobernabilidad y las instituciones democráticas, socava el estado de derecho y exacerba la desigualdad. Para esta Comisión, el Poder Judicial juega un rol esencial en su control:

La impunidad fomenta y perpetúa los actos de corrupción. Por lo tanto, el establecimiento de mecanismos efectivos para erradicar la corrupción es una obligación urgente para lograr un acceso efectivo a una justicia independiente e imparcial y para garantizar los derechos humanos (Resolución $\mathrm{N}^{\circ} 1 / 18 \mathrm{CIDH}$ ).

En el caso del derecho interno, los actos descriptos más arriba se encuentran tipificados en Código penal argentino dentro de los Delitos contra la Administración pública, desde los artículos 237 y siguientes, entre los que destacan, malversación de fondos, abuso de autoridad y violación de los deberes de los funcionarios públicos, negociaciones incompatibles con el ejercicio de funciones públicas, entre otros. Como se ha señalado, estos tipos penales tratan de prevenir

\footnotetext{
${ }^{82}$ Internalizada en Argentina por Ley No 26.097.
} 
conductas anormales que persigan el logro de aumentos patrimoniales prevaleciéndose de la condición de funcionario por parte del agente, o que se protege el decoro, la dignidad, y la insospechabilidad de la administración pública, la imagen de transparencia, gratuidad, y probidad de la administración y quienes la encarnan, o sencillamente, el deber de acreditar los motivos del enriquecimiento (D’Alessio 2005: 864 t. II).

\section{EL PODER JUDICIAL COMO ÓRGANO DE CONTROL}

Para Jiménez de Parga (2009) la caracterización legal de la corrupción resulta insatisfactoria pues este tipo de definición no es más que un listado de los tipos penales. Cree, por el contrario, que son determinantes los valores que configuran la organización social. Si bien este tipo de conceptualización resulta adecuada cuando lo que se están analizando son los desvíos disruptivos de ciertos valores sociales determinados esenciales, cuando estudiamos el fenómeno desde el punto de vista del Poder Judicial, no podemos ampliar su base su riesgo de politizar la justicia.

Esta última afirmación requiere un mayor detalle. De acuerdo con la teoría constitucional clásica, en los sistemas políticos republicanos, como los de América Latina, las actividades estatales fueron divididas en tres campos separados, cada uno de ellos asignados a un cuerpo de magistrados: el Ejecutivo al Presidente, el Legislativo al Congreso y el Judicial a los Tribunales ${ }^{83}$. Sin embargo, Loëwenstein (1976) ha propuesto una versión más realista aplicando una nueva división tripartita: determinación de la decisión, ejecución de la decisión y control político. Es en este último aspecto, que el Poder Judicial juega un rol fundamental.

En la concepción originaria de Montesquieu (2007), la función judicial se debería limitar a ejecutar la decisión política y no extenderse a las otras dos funciones. Sin embargo, el Poder Judicial se ha constituido en un auténtico detentador del poder a través del control de la constitucionalidad de los actos, normas y leyes emitidas por el gobierno y el parlamento ${ }^{84}$.

En materia de control de constitucionalidad, este control político ha tenido auto limitaciones que tienden a atenuar lo que implicaría una absoluta supremacía de la justicia sobre los otros poderes. Los tribunales que han seguido el modelo norteamericano, como en

\footnotetext{
${ }^{83}$ En este sistema de separación funcional por división subjetiva de las atribuciones, a cada uno de estos campos se concedió al respectivo detentador del poder una autonomía y monopolio de acción, no pudiendo ser violado este ámbito por ninguno de los otros detentadores del poder.

${ }^{84} \mathrm{El}$ control de la constitucionalidad es esencialmente un control político y cuando se impone frente a los otros poderes, es en realidad una decisión política. Este control, de creación pretoriana en los EE.UU. por el Chief Marshall, se hace altamente discutible cuando los jueces proclaman su derecho de valorar una decisión política, social o económica. Es en estos casos cuando el Poder Judicial se transforma en verdadero poder de control político.
} 
Argentina, no deciden sino en casos y litigios auténticos, rigiendo el principio de que la voluntad del Congreso debe ser respetada cuando no viole abiertamente la Constitución. Pero el principio que más ha limitado la función del control político ha sido no actuar sobre las llamadas political questions que no son revisables por ser actos realizados en ejercicio de facultades privativas y exclusivas de otro órgano del poder. Este aspecto tan debatido y criticado ha sido sin embargo el punto de equilibro entre los Poderes Legislativo y Ejecutivo frente al Poder Judicial, dique éste que sirvió de contención al tan temido peligro que implicaría el gobierno de los jueces ${ }^{85}$.

En el caso del control de los delitos de corrupción, la problemática es similar: obligado a mover su lento aparato burocrático ante cada denuncia, el Poder Judicial se encuentra en medio de fuertes presiones políticas y sociales: si no activa la denuncia de la oposición, es acusado de ser dependiente del poder de turno; si no activa la denuncia del oficialismo sobre sectores de la oposición, también él es opositor; si activa la denuncia contra el gobernante, es destituyente; si activa la denuncia contra grupos de la oposición, es un perseguidor. Estas contradicciones son propias de la temática de la corrupción porque, como hemos señalado más arriba, son acciones reprochables que se cometen desde el poder político ${ }^{86}$. El nudo gordiano sólo se corta si el Poder Judicial se aboca al control legal de la corrupción y esta competencia está dada por el estricto control de la tipificación de las acciones dentro de las previsiones penales.

Ahora bien, ¿desde qué perspectiva estudiar el control de la corrupción por el Poder Judicial? Entendemos que es desde una visión politológica aún cuando el control sea, como mencionáramos más arriba, un control de legalidad. En efecto, entendemos con Foucault (1976) que en las sociedades occidentales, la elaboración del pensamiento jurídico se ha desarrollado esencialmente en torno al poder: a petición del poder real, en su provecho y para servirle de instrumento o de justificación, se ha construido el edificio jurídico de nuestras sociedades $^{87}$. Desde el discurso de verdad se generará una verdad, un relato legitimado por

\footnotetext{
85 Es evidente que este dique hoy se está transformando y pasa a ser más que una autolimitación, una heterolimitación condicionada por las constantes y crecientes demandas al sistema judicial.

${ }^{86}$ Un Poder Judicial desbordado de tales demandas y presiones o bien adopta decisiones de control político sobre los restantes poderes o bien cae en el desprestigio que se debate sobre la política. Pero tanto en uno como en otro caso, el Poder Judicial se politiza y las consecuencias de la política, tanto en su faz agonal como arquitectónica, se trasladan al ámbito de la justicia. Además de la politización de la justicia, se produce asimismo la judicialización de la política cuando miembros del Poder Legislativo, del Ejecutivo, partidos políticos y sectores de presión recurren al ámbito judicial para dirimir sus conflictos intra e interpoderes pretendiendo obtener ventaja política mediante la denuncia de delitos de corrupción.

${ }^{87} \mathrm{El}$ autor se pregunta qué reglas de derecho ponen en marcha las relaciones de poder para producir discursos de verdad o qué tipos de poder es susceptible de producir discursos de verdad que están dotados de efectos tan poderosos.
} 
otros que luego llegarán a la acción. El Poder Judicial y sus distintos actores, generan su relato, su discurso de verdad, en relación a otros poderes en la sociedad para legitimarse y que su relato encuentra su sustento en ésta ${ }^{88}$. Esta construcción resulta esencial para el estudio de los fallos sobre corrupción porque nos permite comprender que son los jueces y fiscales (y no las normas) quienes determinan qué pruebas y cuantas son suficientes para investigar un caso de corrupción y cuándo investigarlo.

Daniel Alberto Sabsay (2004) afirma que la independencia de la justicia es uno de los puntos fundamentales para que se constituya un Estado de Derecho. Pero en Argentina, con su cultura política plasmada en muchos años de personalización de poder, caudillismo, y condiciones por un pasado autoritario, dificultan que se cumpla efectivamente una justicia independiente de los otros dos poderes del estado.

Según Álvaro Herrero (2011) la relación entre la Corte Suprema de Justicia y el Poder Ejecutivo, depende del poder del segundo en el Poder Legislativo ya que si el Ejecutivo controla las cámaras del Congreso Nacional, la Corte se ve claramente afectada para tomar decisiones judiciales. En otras palabras:

La idea central es que en ambientes donde la fragmentación política es la norma, el poder judicial es capaz de crear una doctrina de independencia judicial sin temor de recibir represalias políticas, ya sea en la forma de una enmienda constitucional que limite su poder de revisión, una destitución de miembros de la Corte o un aumento en el número de sus integrantes (Iaryczower, Spiller y Tommasi, 2002:58-59).

Como menciona Gargarella (2011), el Poder Judicial tiene una estrecha relación con el poder político y hasta a veces es una relación condicionada por los mismos actores. Pero a la vez, destaca la relación y la dependencia que tiene el Poder Judicial con el clamor popular debido a las decisiones que toman.

Según Helmke (2003) el incentivo de los jueces para adoptar un comportamiento estratégico es potencialmente mucho mayor en las democracias en vías de desarrollo que en las desarrolladas. Además, dependiendo del futuro político del gobierno, "si los jueces piensan que se verán más limitados en su accionar por el futuro gobierno que se opone al actual, su reacción más apropiada tal vez sea no apoyar al gobierno actual, sin defeccionar a éste” (Helmke, 2003: 182). De allí que en los fallos acerca de corrupción, los jueces que

\footnotetext{
${ }^{88}$ Desde esta perspectiva politológica puede comprenderse los resultados del estudio de Ignacio Labaqui (2003) en su trabajo Las causas de corrupción: un estudio comparado, quien analiza los casos de corrupción en 107 países y los relaciona con el nivel de desarrollo que tienen los países, la libertad económica y la calidad de democracia. Labaqui afirma que un mayor desarrollo y libertad económica inhibe los casos de corrupción, mientras que con el nivel de democracia la relación no es lineal ya que en algunos autoritarismos se ha encontrado menos casos de corrupción. En nuestra visión, estas variables no son lineales porque corrupción y democracia son dependientes de la variable "poder" y directamente afectan al sistema político.
} 
tienen que juzgar, no sólo los hechos tipificados, sino en primer término, al gobierno actual y evaluar además, el control que tenga en el Consejo de la Magistratura o sobre el Congreso Nacional, por una eventual remoción o juicio político.

\section{DESARROLLO. La doctrina de los fallos de María Julia Alsogaray, Emir Fuad Yoma y Cristóbal López y otros}

No hay nada que conmueva más al poderoso que la vara que sobre él vaya a aplicársele cuando ya no esté en poder. Las decisiones del Poder Judicial son esa vara: son sus acciones actuales las que permiten prever los resultados de la acción política en el futuro. De allí que años sin juicios con condenas sobre corrupción hayan afectado el actual funcionamiento de los poderes públicos, cuyos titulares no encuentran más límite que el control social, tal vez, una vez cada dos años, elecciones mediante.

Sin embargo, como recientemente ha dicho recientemente uno de los integrantes de la Sala 1 de la Cámara Criminal y Correccional Federal en una de las causas donde estuvo detenido en forma preventiva el ex vicepresidente de la Nación, Amado Boudou,

\footnotetext{
Las obligaciones convencionales asumidas por el Estado implican que éste debe investigar, juzgar y sancionar a los culpables de tales delitos, conforme señala el preámbulo de la Convención de las Naciones Unidas contra la Corrupción "por la gravedad de los problemas y las amenazas que plantea la corrupción para la estabilidad y seguridad al socavar las instituciones y los valores de la democracia, la ética y la justicia y al comprometer el desarrollo sostenible y el imperio de la ley (CFP 1999/2012/7/CA2, 2017:4; voto del Dr. Leopoldo Bruglia).
}

Resulta relevante, entonces, realizar la exégesis de estos tres fallos, todos ellos de repercusión pública, pues nos permitirán identificar, a partir de su doctrina, ciertos criterios que ha tenido el Estado argentino para proteger (o no) sus instituciones.

4.1 Stancanelli, Néstor Edgardo y otro s/ abuso de autoridad y violación de los deberes de funcionario público s/ incidente de apelación de Yoma, Emir Fuad.

En 2001, la Corte tuvo oportunidad para expedirse en relación al recurso de hecho deducido por la defensa de Emir Fuad Yoma en la causa "Stancanelli, Néstor Edgardo y otro s/ abuso de autoridad y violación de los deberes de funcionario público". En dicha causa, la sala II de la Cámara Nacional de Apelaciones en lo Criminal y Correccional había confirmado 
la resolución de primera instancia con el procesamiento y la prisión preventiva de Emir Fuad Yoma en orden al delito de asociación ilícita en carácter de organizador.

El recurrente tachó de arbitrario el fallo sobre la base del exceso e irrazonabilidad con que se interpretó el alcance de la figura de asociación ilícita y el agravante de organizador con el que se lo señaló. Según el recurrente, lo resuelto por el tribunal a quo habría violado los principios de inocencia, defensa en juicio, debido proceso e igualdad ante la ley, todos amparados en la Constitución nacional.

En este fallo la Corte Suprema deja sin efecto la sentencia por faltar, aun con la provisionalidad de una resolución del tipo de la dictada (procesamiento y prisión previentiva), la consideración fundada acerca de la existencia del acuerdo de voluntades explícito o implícito que caracteriza a la figura de la asociación ilícita ni explicitar con claridad cuáles habrían sido los delitos que la supuesta organización habría encarado. De todo ello, según la Corte, "resulta una decisiva carencia de fundamentación en la resolución atacada, lo que implica que no constituya derivación razonada del derecho vigente". Por ello, declara procedentes la queja y el recurso extraordinario interpuestos y se deja sin efecto la sentencia.

Pero lo más relevante del caso es la exhortación que hace el voto de la mayoría de los jueces del máximo Tribunal a los otros miembros del Poder Judicial:

\begin{abstract}
Que resulta necesario llamar a la reflexión a los señores jueces y fiscales de las instancias inferiores intervinientes en causas de significativa repercusión como la presente sobre la necesidad, frente a una opinión pública - sea formada espontáneamente $\mathrm{u}$ orientada por los medios masivos de comunicaciónparticularmente sensible ante hechos, reales o supuestos, de corrupción administrativa, de extremar la atención en el encuadramiento legal de los hechos imputados a funcionarios o ex funcionarios. Pues resulta irreparable el daño producido por la ligereza en la apreciación de tales hechos al crear expectativas públicas de punición que, en caso de quedar luego desvirtuadas, alimentan sospechas o interpretaciones torcidas o aun malévolas sobre la intención de los órganos judiciales que en definitiva hacen respetar el ordenamiento jurídico.

Nada se resuelve creando delitos de la nada ni buscando el tipo penal que permita el procesamiento con efectiva privación de la libertad para luego acomodar los hechos a la figura, invirtiendo así el orden lógico del razonamiento. Demasiados problemas han ocasionado a la república las represiones ilegales del pasado para que ahora se intente la represión de los delitos contra la administración o que perjudiquen el erario público por caminos aparentemente revestidos de legalidad pero en definitiva ilegales.

No es cuestión de satisfacer a la opinión pública presentándose como adalides de la lucha contra la corrupción administrativa sino de aplicar rigurosamente el ordenamiento jurídico sancionando mediante la utilización de los medios legítimos suministrados por el derecho a aquellos que lo violan.
\end{abstract}

4.2 Alsogaray, María Julia s/ recurso de casación e inconstitucionalidad. 
María Julia Alsogaray (1942-2017) fue diputada nacional durante los años 1985 y 1989. Fue interventora de la Empresa Nacional de Telecomunicaciones (ENTEL) y de la siderúrgica SOMISA, además fue Secretaria de Recursos Naturales y Ambiente Humano de la Nación Argentina.

El Tribunal Oral en lo Criminal Federal $n^{\circ} 4$ por mayoría había condenado a María Julia Alsogaray a la pena de tres años de prisión e inhabilitación absoluta por seis años, por considerarla autora del delito de enriquecimiento ilícito previsto en el artículo 268 (2) del Código Penal. También ordenó el decomiso de los efectos provenientes del delito por las sumas de quinientos mil dólares y seiscientos veintidós mil pesos. La defensa pública de la nombrada interpuso recursos de casación e inconstitucionalidad, que fueron concedidos. La Sala IV de la Cámara Nacional de Casación Penal, decidió no hacer lugar a esas impugnaciones y declarar la constitucionalidad del artículo 268 (2) del Código Penal.

Cabe destacar que dadas las dificultades para probar esta clase de acciones, el Código Penal argentino crea un tipo penal, el artículo 268 (2), que ha sido cuestionado por invertir la carga de la prueba. El artículo prevé que

Será reprimido con prisión de dos (2) a seis (6) años, multa de dos (2) a cinco (5)
veces del valor del enriquecimiento, e inhabilitación absoluta perpetua, el que al ser
debidamente requerido, no justificare la procedencia de un enriquecimiento
patrimonial apreciable suyo o de persona interpuesta para disimularlo, ocurrido con
posterioridad a la asunción de un cargo o empleo público y hasta dos (2) años
después de haber cesado en su desempeño. Se entenderá que hubo enriquecimiento
no sólo cuando el patrimonio se hubiese incrementado con dinero, cosas o bienes,
sino también cuando se hubiesen cancelado deudas o extinguido obligaciones que lo
afectaban (artículo 268 (2), Código Penal).

Parte de la doctrina, como Creus (1981), ha señalado que es un delito que se origina en la conducta de un sujeto (no justificar), otra señala que resulta un tipo penal violario del Estado de Derecho por afectar la garantía constitucional de no declarar contra sí mismo (Sancinetti, 2000, por ejemplo).

Elevada la causa a la Corte sólo respecto a la validez constitucional del citado artículo del Código penal, el entonces Procurador General, Esteban Righi, en 2007 recordó la intervención previa de los órganos judiciales, donde se había afirmado que:

el bien jurídico tutelado es el interés público por la transparencia y probidad en el desempeño de los funcionarios, y que se lo lesiona mediante el enriquecimiento apreciable e injustificado del agente público durante la vigencia de la relación funcional, lo cual constituye la acción típica.

la esencia del tipo penal radica en el enriquecimiento patrimonial apreciable e injustificado. En cuando al adjetivo apreciable dijo, con sustento en el proyecto de 1941, que por tal debe entenderse aquel que resulta considerable con relación a la situación económica del agente al momento de asumir el cargo y que no está de 
acuerdo con las posibilidades de evolución normal de aquella durante el tiempo e su función

Con relación a la inversión de la carga de la prueba alegada, entendió, junto con el Tribunal Oral en lo Criminal Federal $\mathrm{n}^{\circ} 4$, que al corresponder exclusivamente al órgano jurisdiccional y al ministerio público la demostración previa del incremento patrimonial de aquéllas característica, la oportunidad de explicar que brinda el requerimiento importa una garantía en favor del funcionario, y la falta de justificación o su insuficiencia no permiten sostener que exista presunción de culpabilidad, pues ello no se valora negativamente por imperio del artículo 18 de la Constitución que asegura no sólo el derecho a negarse a declarar, sino también el de defensa en juicio, en cuya virtud el sospechado puede optar por probar o no la licitud de su enriquecimiento ${ }^{89}$.

La Corte Suprema de Justicia de la Nación compartió e hizo suyos los términos y conclusiones del dictamen del señor Procurador General ${ }^{90}$ por lo que la constitucionalidad de este tipo penal ha sido reconocida por la máxima instancia del Poder Judicial.

4.3 Causa López, Cristóbal Manuel y otros s/ defraudación contra la Administración Pública.

Los procesados en esta causa son Cristóbal Manuel López, Carlos Fabián de Sousa y Ricardo Daniel Echegaray. Los dos primeros son dueños del grupo Indalo, principales accionistas y dueños de Oil Combustibles, entre otras empresas. Ricardo Echegaray, fue ex Administrador Federal de Ingresos públicos, entre los años 2008 y 2015.

Dicha causa tramitó en primera instancia por el Juzgado Criminal y Correccional Federal $\mathrm{n}^{\circ} 10$ a cargo del Dr. Julián Daniel Ercolini. En el fallo de procesamiento, de fecha de 19 de diciembre de 2017, el juez señala que las evidencias agregadas a la causa permiten corroborar provisionalmente la hipótesis inicial de imputación respecto del imputado Echegaray, quien, al frente de la Administración Federal de Ingresos Públicos, tenía la potestad de dirigir al organismo, ejercer las facultades que las leyes le asignaban a la AFIP y percibir, recaudar, exigir y ejecutar los tributos; actividades que fueron ejercidas de manera direccionada de acuerdo a la conveniencia del caso para beneficiar a la contribuyente Oil Combustibles S.A.

\footnotetext{
${ }^{89}$ En el caso, al ser intimada del hecho atribuido se le hizo saber que consistía en haberse verificado un apreciable incremento patrimonial a partir del año 1991 y durante su desempeño en la función pública y que al serle requerida la explicación sobre el origen de dicho incremento, procuró justificarlo declarando diversos ingresos de significancia y aportando, documentación respaldatoria presumiblemente falsa o generando al efecto instrumentos que no reflejarían la verdad.

${ }^{90}$ Votos del Dr. Lorenzetti, Dra. Highton de Nolasco, Dr. Fayt, Dr. Petracchi, Dr. Maqueda, Dr. Zaffaroni y Dra. Argibay.
} 
Uno de los argumentos de la defensa del ex funcionario está vinculado con el funcionamiento burocrático del Estado y la intervención de distintas áreas hasta llegar a su decisión. En efecto, Echegaray pretendió exculparse señalando que

\begin{abstract}
el aporte de las áreas centrales y operativas no constituyeron un simple "pasa mano", sino que cada funcionario que participó en las actuaciones lo hizo en función de su rol específico y con el fin de aconsejar que se otorgara el plan de pago al contribuyente en función de los elementos con los que contaba, como así también objetar, desaconsejar o no prestar conformidad a que ello ocurriera y detener las actuaciones para requerir nueva información (CFP 4943/2016 2017:18).
\end{abstract}

Sin embargo, el juez señaló que el hecho de que la evaluación del funcionario haya encontrado sustento en lo manifestado por sus dependientes, no lo eximía de responsabilidad alguna ya que la concesión o el rechazo de un plan dependía únicamente de la evaluación que efectuara respecto de la situación económico financiera que impidiera el pago, lo que no fue realizado.

Otra posible excusación fue también tratada por el juez, la supuesta discrecionalidad para dictar la medida. En efecto, sostuvo Echegaray que en lo que hace a los planes particulares de pago el art. 32 de la Ley $\mathrm{N}^{\circ} 11.683$ le daba el poder de concederlos cuando el contribuyente tuviera dificultades económico-financieras, pero que este aspecto no era regulado por la ley, por lo que su valoración era discrecional. A ello, el juez señaló que

\footnotetext{
Más lo manifestado por Echegaray en cuanto a la discrecionalidad que poseía para resolver asuntos de esta naturaleza, tampoco logra conmover al suscripto, en tanto ese argumento no desplaza ni puede desplazar los requerimientos fijados por la ley en tal sentido (CFP 4943/2016 2017:55).
}

La causa fue apelada ante la Sala I de la Cámara Criminal Correccional Federal. Respecto a la discrecionalidad, la Cámara entendió que:

Concretamente, en el caso de autos, no advierto que la imputación encierre un cuestionamiento a la política tributaria llevada adelante por el Dr. Echegaray como titular de la AFIP. Sino que, en todo caso, el reproche está dirigido a la conducta desplegada desde su rol de máxima autoridad del organismo, que por acción (otorgamiento de planes particulares) u omisión (acogimiento del contribuyente a planes generales) habría beneficiado a los dueños de Oil Combustibles S.A., a través de la concesión irregular de planes de facilidades de pago, permitiéndoles prorrogar sistemáticamente la obligación de ingresar ese tributo, en perjuicio del Fisco (CFP 4943/2016 2018:37, CCCF - Sala I).

El procesamiento fue luego apelado ante la Sala I de la Cámara Federal de Casación Penal, que el 27 de abril de 2018 confirma en su totalidad el fallo de procesamiento y prisión preventiva de primera instancia. 


\section{CONSIDERACIONES FINALES}

Entendemos que el control de la corrupción no es un problema del Poder Judicial sino un problema social ya que es un disvalor que afecta a la ciudadanía en su conjunto. Todos los órganos públicos están llamados a efectuar y profundizar sus sistemas de control ya sea mediante auditorías, procesos públicos de compras, leyes de acceso a la información pública, concursos para el ingreso a los cargos públicos, entre otros. Sin embargo, y dado que nuestro sistema de control político es popular, no puede el Poder Judicial efectuar el control político de la corrupción sino sólo el control legal cuyas acciones están tipificadas en los códigos penales o leyes especiales: así, entendida la corrupción como una práctica delictiva, es el Poder Judicial la última instancia que efectúa el control cuando los sistemas preventivos fallan $^{91}$.

Hemos transcripto de los fallos analizados aspectos sustanciales para el control judicial de la corrupción: la necesidad de razonabilidad y fundamentación del propio Poder Judicial para tratar y sustanciar este tipo de delitos en el primer caso; constitucionalidad de un tipo penal que permitiría eficazmente perseguir los efectos de la corrupción fácilmente identificables con el aumento patrimonial; limitación a la eximición de responsabilidad por las actividades y controles de los órganos inferiores y por criterio de discrecionalidad en el ejercicio del poder político, en el último fallo. Estos criterios constituyen una red sólida para la actuación del Poder Judicial.

Estas tres variables, sobre la razonabilidad del propio Poder Judicial, el enriquecimiento ilícito dentro del artículo 268(2) del Código Penal Argentino y la discrecionalidad del poder político, entendemos que son las que les permitiría con mayor eficacia a los jueces y fiscales juzgar, investigar y controlar los delitos de corrupción por parte de los funcionarios públicos, aquellos que son de carrera administrativa y los funcionarios públicos de cargo políticos que duran gestiones y luego dejan el poder.

Sin embargo, el otro dato político es la temporalidad. Todos son fallos de funcionarios fuera del Poder. De allí que resulte esencial también remarcar que en estas causas tiene una relevancia significativa quién es el imputado y qué lugar ocupa en el sistema político: el caso de Emir Fuad Yoma, uno de los principales asesores del ex presidente Carlos Menem, es consecuencia del escándalo de la venta de armas a Ecuador y Croacia, sucedida en 1991 y

\footnotetext{
${ }^{91}$ Siempre queda al pueblo, como titular de la soberanía, el control político de la corrupción.
} 
1995 respectivamente. La causa que estudiamos llega a la Corte en 2001 y su sobreseimiento es de 2013 cuando se condena a Carlos Saúl Menem y Oscar Camilión, más de quince años de ocurridos los hechos. En el caso de Alsogaray, la condena del Tribunal Oral en lo Criminal Federal n4 llega en 2004, habiendo finalizado la función pública en 1999; con apelaciones, el dictamen del Procurador que analizamos, fue 2007. Menos tiempo sucede en el tercer caso analizado, pues llega Echegaray al procesamiento en 2017 poco más de casi dos años luego de finalizar su cargo de Administrador Federal de Ingresos Públicos, y menos de unos años luego de dejar el cargo de Auditor General de la Nación (AGN).

Este patrón temporal afecta el control, al Poder Judicial y a la democracia en su conjunto. En efecto, el tiempo de las investigaciones es crucial por su impacto en el sistema político: la falta de certezas afecta al debido proceso y afecta, como señalamos, daña al sistema político en su integralidad.

\section{REFERENCIAS}

ABRAMOVICH, V. (1992). Todos los jueces son crustáceos. No Hay Derecho, 3, $\mathrm{N}^{\circ} 8$, Diciembre.

ARGENTINA, Código Penal de la Nación Argentina. Ley 11.179. T.O. 1984. Actualizado. Disponible en http://servicios.infoleg.gob.ar/infolegInternet/anexos/1500019999/16546/texact.htm Acceso en: 16/11/2018.

ARGENTINA, Sentencia de la Cámara Criminal y Correccional Federal Sala 1. CFP 4943/2016/19/CA6. Disponible en www.cij.gov.ar/d/sentencia-SGU-201444274.pd. (2017)

Argentina, Sentencia de la Cámara Criminal y Correcional Federal Sala 1 CFP 1999/2012/7/CA2. Disponible en file:///C:/Documents\%20and\%20Settings/e1c851a/Mis\%20documentos/Downloads/fallo\%20( 3).pdf Acceso en: 16/11/2018.

ARGENTINA, Sentencia del Juzgado Criminal y Correcional Federal n ${ }^{\circ}$ 10. CFP 4943/2016. Disponible en https://www.cij.gov.ar/nota-28908-El-juez-Ercolini-proces--con-prisi-npreventiva-a-Crist-bal-L-pez-y-Fabi-n-De-Sousa-y-orden--sus-detenciones.html Acceso en: 16/11/2018.CHERYL W. Gray y Daniel KAUFMAN (1998). Corrupción y desarrollo. Finanzas \& Desarrollo / Marzo de 1998. Disponible en http://siteresources.worldbank.org/INTWBIGOVANTCOR/Resources/gray_spanish.pdf Acceso en: 16/11/2018. 
ARGENTINA. Dictamen del Procurador General de la Nación Argentina en la causa "Alsogaray, María Julia s/ recurso de casación e inconstitucionalidad" S.C. A 1846; L. XLI. Disponible en https://www.mpf.gob.ar/procelac-ap/files/2013/10/Dictamen-PGN-causaAlsogaray.pdf. Acceso en: 16/11/2018.

ARGENTINA. Ley 24.759. Convención Interamericana Contra la Corrupción. Sancionada 1996. Promulgada $1997 . \quad$ Disponible en http://servicios.infoleg.gob.ar/infolegInternet/anexos/40000-44999/41466/norma.htm Acceso en: $16 / 11 / 2018$.

ARGENTINA. Ley 26.097. Convención de Naciones Unidas contra la Corrupción. Sancionada y promulgada en 2006. Disponible en http://servicios.infoleg.gob.ar/infolegInternet/anexos/115000-119999/116954/norma.htm Acceso en: 16/11/2018.

CREUS, Carlos (1981). Delitos contra la administración pública: comentario de los artículos 237 a 281 del Código Penal. Buenos Aires: Astrea

D’Alessio, Andres J. (2005). Código Penal Comentado y Anotado. Buenos Aires: La Ley.

FOUCAULT, Michel. Microfísica del poder. Curso del 7 de enero de 1976. Madrid: Las ediciones de la Piqueta, 1980.

GARGARELLA, Roberto. La justicia frente al gobierno: sobre el carácter contra mayoritario del poder judicial. Pensamiento Jurídico Contemporáneo 3. Quito: Corte Constitucional para el Período de Transición, 2011.

HELMKE Gretchen. La lógica de la defección estratégica: relaciones entre la Corte Suprema y el Poder Ejecutivo en la Argentina entre los períodos de la dictadura y la democracia. Desarrollo Económico. Vol. 43 n¹70, julio-septiembre, 2003.

HERRERO, Álvaro. La incidencia de la Corte Suprema de Justicia en la formulación de políticas públicas: una exploración empírica del caso argentino, en Revista Política Vol. 49 № 1, págs. 71-106, 2011.

IARYCZOWER, Matías, SPILLER, Pablo T. TOMMASI, Mariano (2002) Un enfoque estratégico para entender el comportamiento de la Corte Suprema de Justicia de la Nación. Documento $42 . \quad$ Disponible en https://www.researchgate.net/publication/238065638_Un_enfoque_estrategico_para_entender 
_el_comportamiento_de_la_Corte_Suprema_de_Justicia_de_la_Nacion $16 / 11 / 2018$.

JIMENEZ DE PARGA, Manuel. La corrupción en la democracia. CORBETTA Juan Carlos y PIANA, Ricardo Sebastián. Ensayos sobre la Democracia Contemporánea, La Plata: EDULP, 2009.

KLITGAARD, Robert. Controlando la corrupción. La Paz: Quipus, 1992.

LABAQUI, Ignacio.. Las Causas de corrupción: un estudio comparado. Colección AÑO IX $\mathrm{N}^{\mathrm{o}} \quad$ 14. $\quad$ págs. $155-196,2003.20$ Disponible http://erevistas.uca.edu.ar/index.php/COLEC/article/view/738/708 Acceso en: 16/11/2018.

LATINOBARÓMETRO. ONG. Informe Anual 2017. Disponible en file:///C:/Users/Notebook-Lenovo/Downloads/F00006433-InfLatinobarometro2017.pdf Acceso en: 16/11/2018.

LATINOBARÓMETRO. ONG. Informe Anual 2017. Disponible en file:///C:/Users/Notebook-Lenovo/Downloads/F00005843-Informe_LB_2016\%20(2).pdf Acceso en: 16/11/2018.

LÖEWENSTEIN, Karl. Teoría de la Constitución. Barcelona: Ariel, 1976.

MONTESQUIEU Charles-Louis de Secondat. Del espíritu de las leyes. Buenos Aires: Losada, 2007.

ORSI, Omar Gabriel y GARCÍA Nicolás Rodriguez. Transparencia, acceso a la información y tratamiento penal de la corrupción. C.A.B.A.: Del Puerto, 2011.

PIANA Ricardo S. y AMOSA Fernando M. El derecho de acceso a la información pública en la Provincia de Buenos Aires Aspectos normativos y jurisprudenciales. Redea. Derechos en acción | Año 3 Nº 6, pág. 246-277, 2018.

POSADA CARBÓ, Eduardo. Corrupción y democracia: la rebelión del ciudadano indignado. Claves de razón práctica. Número 45. págs. 16-23, 1994.

RUIZ, Ivan. Según una auditoría, sólo el $2 \%$ de los acusados de corrupción son condenados. La nación. 12 de julio de 2018. Disponible en https://www.lanacion.com.ar/2152492-segun- 
una-auditoria-solo-el-2-de-los-acusados-de-corrupcion-son-condenados $16 / 11 / 2018$.

SABSAY Daniel. El juicio político a la Corte Suprema en la República Argentina. Anuario Iberoamericano de Justicia Constitucional. Número 8. p. 493-519, 2004.

SANCINETTI, Marcelo. EI delito de enriquecimiento ilícito de funcionario público - art. 268, 2, C.P.- Un tipo penal violatorio del Estado de Derecho. Buenos Aires: AD-HOC, 2000 .

TODARELLO Guillermo Ariel. Corrupción administrativa y enriquecimiento ilícito. C.A.B.A.: Del Puerto, 2008.

TUSELL, Javier. La revolución posdemocrática. CORBETTA, Juan Carlos y Piana, Ricardo Sebastián. Ensayos sobre la Democracia Contemporánea, La Plata: EDULP, 2009.

\title{
CORRUPTION AND JUDICIAL CONTROL IN ARGENTINA. ITS STUDY AFTER A READING OF THE OF EMIR FUAD YOMA, MARÍA JULIA ALSOGARAY AND CRISTOBAL LOPEZ DECISIONS
}

\begin{abstract}
ABTRACT
In this article we study the phenomenon of corruption in Argentina from the analysis of three judgments, relevant both for its media impact and doctrine. This analysis will allow us to infer some guidelines on the operation of the Judiciary. The hermeneutics will be used as a methodology for the study of judgments from a theoretical perspective that integrates the study of law within the social sciences, framing judicial control as a political phenomenon. The article is structured in 3 sections. The first one presents the problem of corruption from a theoretical and normative perspective highlighting its link with the political system; the second, from the control and the Judicial Power and the need to identify control as a non-political control even when it is necessary to study the phenomenon from the political aspects involved; in the third we focus on the study of failures. We conclude that the doctrines of failures that we outlined would allow to create a solid network for judicial control of corruption, although we identify a temporal pattern that affects the effectiveness of control.
\end{abstract}

Keywords: Judicial Power. Corruption. Control. Argentina. 